\title{
MANEIRAS DE COMPREENDER A DEMOCRACIA EM UM ESTADO DEMOCRÁTICO DE DIREITO
}

Henrique Camacho

ISSUE DOI: $10.21207 / 1983.4225 .258$

\section{RESUMO}

O tema democracia envolve diversas searas das ciências sociais aplicadas. Optou-se por apresentar um debate mais voltado para o campo jurídico, de maneira a elucidar, ainda que brevemente e por meio de uma leitura secundária, sobre o conceito de democracia para Hans Kelsen, Carl Schmitt e Hermann Heller, almejando comprovar a evolução do papel da democracia ao longo dos anos, para que então seja possível uma melhor compreensão da forma que foi pensada para ser incluída na Constituição Federal de 1988. Levar-se-ão em consideração as recentes manifestações sociais que culminaram em diversas aglomerações de pessoas, nas diversas capitais do país. Métodos predominantemente dedutivo e indutivo foram utilizados para composição da argumentação ora apresentada.

Palavras-chave: Kelsen. Heller. Schmitt. Democracia. Constituição.

\section{INTRODUÇÃO}


Compreender a democracia é tarefa deveras trabalhosa e árdua. Requer considerável disposição de tempo para analisar uma gama enorme de autores, das mais variadas áreas das ciências sociais aplicadas. Um passo inicial, nesse processo cognitivo, é a estruturação de um debate no campo jurídico, especificamente alguns juristas de relevância para o século $\mathrm{XX}$. Optou-se por analisar as obras e alguns textos escritos por e sobre Hans Kelsen, Carl Schmitt e Hermann Heller. Trata-se, portanto, de uma tentativa de composição de argumentos através de uma leitura secundária dos citados autores, pois, embora alguns excertos não tratem diretamente da democracia, tratam de suas reflexões sobre temática, como também sobre o poder estatal e estruturação do Estado.

Da análise de cada um destes juristas e dos textos escritos por eles ou sobre eles será possível traçar um paralelo, ainda que breve, da composição intelectiva que se tem atualmente do conceito de democracia, principalmente sob a égide da Constituição Federal de 1988. Com o escopo de responder a seguinte indagação: como é possível compreender o significado de democracia em um Estado que se denomina Democrático de Direito e que diuturnamente é flagrado desrespeitando os direitos fundamentais?

Não se deve esquecer que é importante situar-se ao longo de uma evolução histórica do pensamento de juristas e filósofos, bem como da própria evolução da sociedade. Neste ponto, em que se informa sobre a evolução da sociedade, cumpre destacar que há uma linha conectiva quanto a evolução da própria estrutura do Direito como ciência e também do Estado como ente político e garantidor dos direitos fundamentais e das determinações da Constituição.

Impossível ignorar, para a estruturação das linhas que seguem, as recentes movimentações sociais, que levaram diversas pessoas às ruas em prol de uma demonstração do inconformismo social com a atual situação brasileira, em que quantidades exorbitantes foram e continuam sendo gastas para a estruturação de eventos festivos e esportivos sem que seja tomada ação efetiva alguma para melhoria da saúde pública, educação e segurança pública: não se trata de uma denegação da efetividade dos direitos fundamentais promovida às vistas do próprio Estado? Esses movimentos sociais que se iniciaram com a divulgação de informação pelas redes sociais virtuais podem ser vistos como parte de um processo de estruturação de uma cultura política mais democrática dos cidadãos brasileiros? 
Para os argumentos trabalhados, constata-se utilização predominante de uma metodologia que deve superar a dogmática-jurídica, por não ser fundamentada unicamente em texto normativo, mas sim em análise de livros e artigos científicos. Um controle hermenêutico será adotado para a estruturação lógica dos argumentos que serão apresentados, levando em consideração uma análise histórica dos posicionamentos dos juristas em destaque, ainda que de maneira singela, dos conceitos de democracia para alguns juristas e sua concepção frente à Constituição vigente.

\section{A DEMOCRACIA PARA HANS KELSEN}

"Posso lutar e morrer incondicionalmente pela liberdade que a democracia é capaz de concretizar, ainda que possa admitir que, do ponto de vista da ciência racional, meu ideal é apenas relativo"'. É com essa frase da obra de Hans Kelsen que o presente trabalho inicia os apontamentos acerca da democracia.

O jurista em destaque aponta para um conceito deveras diferente do que é possível depreender de boa parte das leituras hodiernas. Diferentemente do que se busca demonstrar nos dias de hoje, Kelsen aponta para os valores impostos pela norma como mais fundamentais do que os impostos pelo povo, pois neste aspecto, a democracia se perfaz de argumentos abertos, como "interesse do povo". Discorre que:

Esta perversão do conceito de democracia, de um governo do povo - e que pode significar, em um Estado moderno, somente um governo de representantes eleitos pelo povo - para um regime político voltado para o interesse do povo, não é apenas teoricamente inadmissível devido a má utilização da terminologia, mas também extremamente problemática em termos políticos. [...] Todo governo pode - e, como já demonstra, todo governo efetivamente o faz - afirmar que está agindo no interesse do povo. Uma vez que não existe nenhum critério objetivo para avaliar o que se chama de interesse do povo, a expressão "governo para o povo"

\footnotetext{
${ }^{1}$ KELSEN, Hans. A democracia. 2. ed. São Paulo: Martins Fontes, 2000. p. 144.
} 
é fórmula vazia, suscetível de ser usada para justificar ideologicamente qualquer tipo de governo. ${ }^{2}$

Desse modo, depreende-se dos ensinamentos acima ilustrados que a imposição de uma democracia "aberta" não pode ser considerada ao se talhar as estruturas de um Estado, independentemente de estar esse incluso nas vestes do liberalismo ou do bem estar social. É a norma que irá disciplinar de maneira reta a possibilidade de sustentação de um Estado cuja denominação resulte no famigerado Estado Democrático:

Kelsen parte de uma visão atomística da sociedade, com a normativização completa do Estado, ou seja, sua dessubstancialização. Para Kelsen, não existe povo, a unidade do Estado só existe na esfera fictícia do ordenamento. A democracia é entendida como racionalidade e calculabilidade, garantia da certeza do direito. A normatividade, para Kelsen, é entendida como normalidade e estabilidade. ${ }^{3}$

Corroborando os argumentos, é possível depreender de algumas obras que Kelsen entende ser possível a democracia mediante a existência de um Estado que, longe de homogêneo em termos sociais ou da execução dos interesses, deve ser entendido como a única entidade capaz de fixar e exercer as instituições democráticas, ainda que essas não denotem a representação integral de todas as demandas e preferências dos indivíduos. Em outros termos, esse autor estabelece a necessidade da positivação da democracia como forma de garantir a falência daqueles que entendem haver necessidade de um governo mais autoritário e absoluto. Os conceitos vagos e abertos criados pelo povo e cujas bases estão dispostas no ideal popular possibilitam o surgimento dos "defensores do povo". Todavia, enaltecem a tirania:

Ficará, então, mais fácil de compreender o motivo pelo qual uma genuína ciência política pode prosperar mais em uma democracia, onde sua liberdade e sua

\footnotetext{
${ }^{2}$ KELSEN, Hans. A democracia. 2. ed. São Paulo: Martins Fontes, 2000. p. 147-148.

${ }^{3}$ BERCOVICI, Gilberto. Soberania e constituição: para uma crítica do constitucionalismo. São Paulo: Quartier Latin, 2008. p. 22.
} 
independência do governo estão asseguradas, do que em uma autocracia, onde só as ideologias políticas podem desenvolver-se, e também por qual razão aquele que prefere a democracia à autocracia inclinase fortemente ao um conhecimento científico da sociedade em geral, e do Estado e do Direito em particular, do que aquele cuja natureza o empurra para a autocracia e, desse modo, para uma atitude ideológica. $^{4}$

A principal preocupação que deve ter a democracia, enquanto regime de governo e também como braço da Ciência Política, é que por intermédio dela outros valores, tais como a liberdade e a igualdade, sejam respeitados.

Portanto, não é condizente com o conceito de democracia a imposição, por parte de qualquer pessoa, de seu posicionamento em detrimento da vontade ou necessidade dos outros, de seus iguais. Neste ponto, vale dizer que uma democracia se perfaz não simplesmente da vontade da maioria, mas em certos pontos, da melhor hipótese para o debate entre as maiorias e as minorias. Dito de outro modo: é necessário, em uma democracia, que as minorias tenham a oportunidade de demonstrar seus argumentos para que, a depender da dialética empregada, possam vir a se tornar a maioria. $^{5}$

"A doutrina de Kelsen exprime o Estado legal", logo "Não há, portanto, Estado Legal injusto. Todo Estado é um Estado de Direito, nesse sentido". ${ }^{6}$ É possível compreender que a democracia, nos parâmetros kelsenianos de compreensão do Estado, é a forma adotada pela norma para fazer valer os preceitos mais importantes da vida em sociedade, com destaque para a liberdade e a igualdade.

\section{A DEMOCRACIA PARA HERMANN HELLER}

\footnotetext{
${ }^{4}$ KELSEN, Hans. A democracia. 2. ed. São Paulo: Martins Fontes, 2000. p. 194.

${ }^{5}$ Idem. p. 201-203.

${ }^{6}$ FERREIRA FILHO, Manuel Gonçalves. Estado de direito e constituição. 2. ed. rev. e ampl. São Paulo: Saraiva, 1999. p. 42-43.
} 
Herman Heller, jurista alemão, contribuiu imensamente para os debates enfrentados no campo das ciências jurídicas. Não poderia ser diferente, em virtude de ser perceptível, em sua obra, forte influência hegeliana. Para o jurista, a democracia deve imperar como maneira de ser compreendida como uma teoria soberana. Enquadra seus posicionamentos em um patamar intermediário entre os ensinamentos de Hans Kelsen e Carl Schmitt:

Prescindiendo de la línea científica concreta que no lleva a Heller a aproximarse a Kelsen ni a seguir a Schmitt, sina más bien a adoptar uma posición intermedia entre las de ambos, su actitud de conocimento, que es radicalmente distinte de la de aquéllos, se caracteriza por la cuestión, para él fundamental, del por qué y del para qué de Estado y del derecho, superando así el formalismo político, cuestión que, em nuestra época, sólo puede ser resuelta mediante la determinación de la función social de Estado. ${ }^{7}$

Por intermédio de levantamento doutrinário, pode-se dizer que há contraposição de ideias entre Heller e Schmitt e entre Heller e Kelsen. Tal afirmativa pode ser estruturada, pois do excerto transcrito acima, concluise que para Heller há a necessidade de incluir na compreensão da Ciência Política aspectos sociais do papel desempenhado pelo Estado. Para ele, a democracia evolui e passa por momentos influenciáveis pelo Liberalismo e pelo Socialismo. ${ }^{8}$

Esse conceito de democracia, compreendida como o complexo de fatores que compõem a vida em sociedade evolui, de maneira a permitir que a compreensão do real significado de "povo" permita dizer que os estudos de Heller se tornaram pertinentes. E é por traçarem abordagens contrastantes e antagônicas quanto ao conceito de "povo" que, tanto o Libera-

\footnotetext{
${ }^{7}$ HELLER, Hermann. Teoria del Estado. México: Fondo de Cultura Economica, 1942. Manuales introdutórios, v. II. p. 9.

${ }^{8}$ BERCOVICI, Gilberto. Democracia, inclusão social e igualdade. Conselho Nacional de Pesquisa e Pós-graduação em Direito - CONPEDI. Anais do XIV Congresso Nacional do CONPEDI. Anais dos eventos. On-line. 2005. Disponível em <http://www.conpedi.org.br/manaus/arquivos/anais/XIVCongresso/043.pdf>. Acesso em 24 set. 2012.
} 
lismo quanto o Socialismo, na leitura de Heller, desempenharam influências significativas no desenvolvimento do próprio conceito da democracia. Para ele, a democracia é exercida de maneira inversa a que Kelsen impõe, quando argumenta sobre a efetividade da norma, ou seja, numa estrutura piramidal, de baixo (normas infraconstitucionais) para cima (normas constitucionais).

Segundo Heller, o liberalismo contesta a soberania popular por ver no povo um conjunto de indivíduos isolados. Isto não faz sentido em uma democracia. A democracia é a forma consciente de formação da unidade política de baixo para cima, quando o povo, como pluralidade, se constitui a si mesmo, e conscientemente, em povo como unidade. ${ }^{9}$

O homem, nessa concepção helleriana, deve ser compreendido como um ser naturalmente social e essa sociabilidade é que colabora com a evolução da sociedade.

Há, por óbvio, certo posicionamento crítico por parte de Heller, sobre os ensinamentos de Kelsen acerca da imperatividade do Liberalismo e da estruturação do positivismo, que compõem a base de um sistema positivista. Não seria possível simplesmente ignorar os aspectos externos para a compreensão da função da norma. A partir desse pressuposto, é que o homem não é mais visto como um ser eminentemente devoto do poder da norma, mas sim um ser social preocupado em manter-se em condições de vida social. ${ }^{10}$

Ao considerar a necessidade de superação de paradigmas, é necessário olhar para a compreensão da própria democracia como algo não exclusivamente pertencente ao campo das ciências jurídicas, mas sim, como importante pilastra mantenedora dos debates no campo das ciências sociais aplicadas, em que se descobre a necessidade de uma utilização de

\footnotetext{
${ }^{9}$ BERCOVICI, Gilberto. Soberania e constituição: para uma crítica do constitucionalismo. São Paulo: Quartier Latin, 2008. p. 23.

${ }^{10}$ HELLER, Hermann. Teoria del Estado. México: Fondo de Cultura Economica, 1942. Manuales introdutórios, v. II. p. 120 - 125 c/c BERCOVICI, Gilberto. Democracia, inclusão social e igualdade. Conselho Nacional de Pesquisa e Pós-graduação em Direito - CONPEDI. Anais do XIV Congresso Nacional do CONPEDI. Anais dos eventos. On-line. 2005. Disponível em <http://www.conpedi.org.br/manaus/arquivos/anais/XIVCongresso/043.pdf>. Acesso em 24 set. 2012.
} 
uma práxis histórica no processo de formação de consciência humana do que seria a democracia. ${ }^{11}$

A democracia indica que há inter-relação entre o político, o humano, o social, o cultural; enfim, entre diversos universos que compõem a necessária e mais plural identidade dos direitos humanos, mais facilmente colhidos dos textos constitucionais. ${ }^{12}$

Numa tentativa, ainda que singela, de compreender o conceito de democracia em Heller, vale transcrever o seguinte excerto:

No entanto, Heller realça que, para que seja possível a formação da unidade política, deve ser alcançado certo grau de homogeneidade social. A maior ou menor probabilidade na formação da unidade política depende do maior ou menor grau de homogeneidade social. Há, inclusive, um certo grau de homogeneidade social sem o qual não é possível a formação democrática da unidade política, pois partes do povo já não mais se reconhecem na unidade política e não se identificam mais com os símbolos e os representantes do Estado. ${ }^{13}$

Dessa forma, por pressupor a noção de unidade sócio-política, os conceitos de Democracia, Socialismo e Liberalismo para Heller apontam também a ideia de teia social. Importante ressaltar que, nas suas análises, o jurista se vale de métodos históricos e comparados para compreender a vida em sociedade e propriamente desenvolver suas teses de inclusão do homem num contexto social. Parece, e com razão, que o jurista tenta demonstrar que a democracia está ligada à ideia de uma massa de pessoas, comprovadamente ligada por interesses comuns, ainda que essas mesmas não compreendam quais são verdadeiramente esses interesses (que podem ser sociais, econômicos, culturais, etc.).

\footnotetext{
${ }^{11}$ MARTÍNEZ, Alejandro Rosillo. Praxis de liberación y derechos humanos: uma introducción al pensamiento de Ignacio Ellacuría. San Luis Potosí, México: Universidade Autónoma de San Luis Potosí, 2008. p. 99 - 114.

12 Idem. p. $115-132$.

13 BERCOVICI, Gilberto. Democracia, inclusão social e igualdade. Conselho Nacional de Pesquisa e Pós-graduação em Direito - CONPEDI. Anais do XIV Congresso Nacional do CONPEDI. Anais dos eventos. On-line. 2005. Disponível em <http://www.conpedi.org.br/manaus/arquivos/anais/XIVCongresso/043.pdf>. Acesso em 24 set. 2012.
} 
É pertinente observar que dessa ideia de teia social, hoje em dia, com a estrutura criada pela globalização e a rede mundial de computadores, parece razoável afirmar que o autor e douto jurista pré-anunciou a necessidade de inclusão do homem em um contexto, independentemente se está se buscando a compreensão de uma ciência política, da sociologia, da antropologia ou a compreensão da função da norma e do Direito, como evidentemente se preocupam os kelsenianos. O homem, nos tempos atuais, nunca se viu tão inserido num contexto mundial, ressalvadas as evidentes desigualdades sociais, frutos de diversas mazelas sociais, econômicas e políticas, que não incluem quantidade considerável de seres humanos que podem ser considerados excluídos dessa teia social, ainda que virtual. Apenas uma reflexão.

\section{A DEMOCRACIA PARA CARL SCHMITT}

Para Carl Schmitt, a construção do conceito de democracia perpassa por situações que implicam não nas características atinentes à norma nem na possibilidade do povo se valer de características comuns, mas sim, de uma imposição advinda de uma autoridade. Em termos ainda comparativos, a estrutura piramidal kelseniana é composta por uma constituição no topo que determina toda a estrutura do Direito e do Estado; para Heller, os ditames são dados pelo povo, que compõe a base dessa pirâmide e que legitima as formas de governo e do Estado; para Schmitt, haverá a imposição por uma autoridade, que não será a Constituição, mas sim de uma autoridade absoluta, determinada pela vontade do povo:

O poder constituinte, para Carl Schmitt, é a origem concreta da forma política. É a própria exceção, sendo impossível de ser descrito em termos normativos. Seu fundamento é a vontade política existencial, cujo sujeito, na democracia, é o povo. [...] O povo, para Schmitt, está acima e além da constituição, entendendo, portanto, que o poder constituinte não se esgota, permanece existindo ao lado e acima da 
constituição, o que justifica a célebre distinção entre constituição e a lei constitucional. ${ }^{14}$

Pelas ideias de Schmitt, é possível dizer que muito mais que um ideal liberal para comandar a vida em sociedade deve imperar um ideal de isonomia, pois para ele, a igualdade é um princípio político altamente democrático, e portanto, colabora com a defesa da vontade dos iguais que compõem uma mesma sociedade. ${ }^{15}$

De acordo com Carl Schmitt, o oposto da democracia não é a ditadura, mas o liberalismo. [...] entende que a votação secreta individual anula a possibilidade específica do povo reunido. A verdadeira capacidade e função do povo, o fenômeno democrático originário é a aclamação, o grito de aprovação ou recusa de massa reunida. ${ }^{16}$

Nesse ponto, portanto, importante perceber que a igualdade seria compreendida por aqueles que detinham o poder, tratando igualmente os que em mesmas condições econômico-sociais estivessem. Por exemplo, se as massas de proletários subissem ao poder, a democracia se consolidaria e haveria a possibilidade de desobstruir as bases do liberalismo.

Saindo do imperialismo da Constituição, o jurista compreende que haveria a necessidade de um Estado forte, em virtude das estruturas criadas pela própria Constituição e que indica não serem capazes de manter uma unidade política. ${ }^{17}$ Haveria a necessidade de um poder centralizador, tomador das rédeas da sociedade para compor uma estrutura democrática capaz de sustentar a vida do povo.

\footnotetext{
14 BERCOVICI, Gilberto. Soberania e constituição: para uma crítica do constitucionalismo. São Paulo: Quartier Latin, 2008. p. 25-26.

${ }^{15}$ BERCOVICI, Gilberto. Democracia, inclusão social e igualdade. Conselho Nacional de Pesquisa e Pós-graduação em Direito - CONPEDI. Anais do XIV Congresso Nacional do CONPEDI. Anais dos eventos. On-line. 2005. Disponível em <http://www.conpedi.org.br/manaus/arquivos/anais/XIVCongresso/043.pdf>. Acesso em 24 set. 2012.

${ }^{16}$ BERCOVICI, Gilberto. op. cit. p. 27.

${ }^{17}$ BERCOVICI, Gilberto. op cit. Online.
} 
Haveria a composição de um poder natural, estruturado com base em preceitos evidentemente democráticos e protetores do povo, da Constituição e da igualdade entre as pessoas:

Para que se consiga impor a neutralidade, é necessário um Estado forte, pois a solução é política e exige a capacidade de tomada de decisões. A saída é um poder neutralizador, que, utilizando-se dos poderes de exceção, consiga excluir quem é hostil ou estranho à ordem política, podendo jogar a legitimidade contra a legalidade e, assim, excluir o inimigo. ${ }^{18}$

Poder aqui compreendido como a necessária forma de manutenção da ordem, que impõe processo de regulação legal da vida dos cidadãos de um país frente às determinações de um soberano, que teve reconhecida sua capacidade de ser o representante da sociedade, que o colocou como representante do povo.

A ideia de democracia aqui pode ser indicada, ao que se compreende das disposições acerca do autor em comento, como a necessária forma de manter um poder centralizado em um único ente - autoridade - capaz de ditar as regras para que as pessoas possam conviver harmoniosamente em sociedade.

\section{A DEMOCRACIA E A CONSTITUIÇÃO FEDERAL BRASILEIRA DE 1988}

Ao longo do texto, muitas ideias foram apresentadas acerca da conceituação do termo democracia. Preceitua a Constituição Federal, em seu artigo primeiro, que a República Federativa do Brasil constitui-se em Estado Democrático de Direito e que seus fundamentos para composição da República são: soberania, cidadania, dignidade da pessoa humana, valores sociais do trabalho e da livre iniciativa e o pluralismo político.

\footnotetext{
${ }^{18}$ BERCOVICI, Gilberto. Democracia, inclusão social e igualdade. Conselho Nacional de Pesquisa e Pós-graduação em Direito - CONPEDI. Anais do XIV Congresso Nacional do CONPEDI. Anais dos eventos. On-line. 2005. Disponível em <http://www.conpedi.org.br/manaus/arquivos/anais/XIVCongresso/043.pdf>. Acesso em 24 set. 2012.
} 
Analisando as acepções do termo democrático, verifica-se uma origem comum do radical de democracia. Não é de hoje a preocupação com a compreensão dessa temática. Pode-se dizer que para a análise do tema, frente os aspectos da Constituição Federal, é importante ressaltar que a ideia de democracia está intimamente ligada aos fundamentos constitucionais da República, bem como o conceito de que para ser democrático deve influir-se por um "[...] poder que emana do povo e é por ele exercido, diretamente ou por meio de seus representantes eleitos democraticamente". ${ }^{19}$

A inclusão do termo "democrático" deve ser analisada valendose inclusive do momento histórico em que foi elaborada a Constituição Federal Brasileira de 1988. Preocupava-se em manter firmes direitos (sufrágio universal, liberdade, igualdade, dignidade humana, etc.) solidificados pelo mundo após duas grandes guerras mundiais e diversos outros conflitos armados. Conclui-se ser correto afirmar que "[...] não é precipitado inferir, em consequência, que a expressão se vincula a uma concepção socializante do Estado". 20

Posto isto, vale ressaltar o seguinte excerto:

A referência à prática de democracia em algumas cidades gregas, em breves períodos, seria insuficiente para determinar a preferência pela democracia, que se afirmou a partir do século XVIII em todo o hemisfério ocidental, atingindo depois o restante do mundo. Foram as circunstâncias históricas que inspiraram tal preferência, num momento em que a afirmação dos princípios democráticos era o caminho para o enfraquecimento do absolutismo dos monarcas e para a ascensão política da burguesia. ${ }^{21}$

Como é possível depreender, a evolução dos paradigmas políticos, como Liberalismo e Socialismo, contribuíram sobremaneira para a estruturação dos diversos pensamentos acerca de Democracia no campo não

${ }^{19}$ NERY JÚNIOR, Nelson; NERY,Rosa Maria de Andrade. Constituição federal comentada e legislação constitucional. 3. ed. São Paulo: Ed. Revista dos Tribunais, 2012. p. 177. ${ }^{20}$ FERREIRA FILHO, Manuel Gonçalves. Estado de direito e constituição. 2. ed. rev. e ampl. São Paulo: Saraiva, 1999. p. 63.

${ }^{21}$ DALLARI, Dalmo de Abreu. Elementos de teoria geral do Estado. 30. ed. São Paulo: Saraiva, 2011. p. 146. 
apenas das ciências políticas, mas também de outros ramos das ciências sociais aplicadas.

Há de se considerar diversos apontamentos acerca das relações humanas e de como se estruturavam tais relações na composição das estruturas de Estado, principalmente no que tange as relações entre os indivíduos e o próprio Estado. A Democracia, numa concepção talvez moderna, é fruto de uma soma de pensamentos e fatores que levaram as sociedades ocidentais a passarem do absolutismo ao liberalismo, mantendo-se atualmente dentre diversas discussões doutrinárias.

Deve-se considerar que, no absolutismo, o poder do rei sobrepunha-se ao poder econômico. Após a estruturação e império da revolução industrial passou-se a ter o poder econômico ditando as regras sobre o poder político, o que culminou com uma contradição que instigou filósofos e cientistas políticos por todo século XIX: o surgimento da liberal-democracia. $^{22}$

Pode-se considerar que o principal entrave, que gera a citada contradição, deve-se ao fato de que o liberalismo estar condizente mais com liberdade do indivíduo, ou melhor, com a própria ideia de liberdade, enquanto a democracia estar mais condizente com a ideia de igualdade. ${ }^{23}$

Após as duas primeiras guerras mundiais e um período delicado em que duas potências bélicas- EUA e URSS- sobrepunham-se em uma corrida armamentista e espacial, pode-se colher diversos pontos que ficaram abalados quanto à preocupação única em manter a liberdade do indivíduo acima dos poderes do Estado.

Nesse momento passou-se a deliberar, em diversos encontros mundiais, a preocupação com o coletivo, com a pluralidade, deixando-se de lado a preocupação única de manter o indivíduo frente o Estado. As novas determinações seriam para manter parâmetros para uma vida individual inclusa em uma vida social. As constituições que surgiram a partir dessas delimitações tornaram os direitos humanos objetivos a serem alcançados para composição de uma sociedade mais igualitária. Os direitos fundamentais inscritos nessas constituições incluíam direitos individuais e direitos sociais. A democracia passou a ser vista, nessas sociedades ocidentais, como a ferramenta para a concretização de uma sociedade mais plena

\footnotetext{
${ }^{22}$ BONAVIDES, Paulo. Do estado liberal ao estado social. 9. ed. São Paulo: Malheiros, 2009. p. 55.

${ }^{23}$ Ibidem.
} 
e mais harmoniosa, afinal "Uma sociedade democrática sabe que as energias íntimas da subjetividade humana, a razão e a consciência constituem as fontes mais valiosas da vida política". ${ }^{24}$

É possível dizer que existem certas possibilidades históricas que resumem algumas capacidades humanas de alterar a realidade não apenas social, mas também cultural, econômica, política, jurídica e etc. ${ }^{25}$. Assim, é resultado de uma insatisfação social e de um processo de conscientização político-social que se promove uma alteração na realidade em que se encontra a população brasileira, passando de um status quo inerte para um mais ativo - politicamente considerado - em que se deu o encontro de milhares de pessoas em diversas cidades do país para manifestarem-se contra os abusos cometidos pelo poder público, um dos maiores demandados por não garantir, por mitigar, os direitos fundamentais. Uma sociedade democrática não surge do nada:

O que eu quero dizer é que não basta definir uma sociedade democrática por sua estrutura legal. Outro elemento desempenha um papel fundamental, a saber, o fermento ou a energia dinâmica que anima o movimento político e que não pode ser inscrita em qualquer constituição nem incorporada a qualquer instituição, já que essa energia é, por natureza, a um tempo pessoal e contigente, assim como fundada na livre iniciativa. Quisera chamar a esse fator existencial um fator profético. A democracia não pode passar sem êle. O povo precisa de profetas. ${ }^{26}$

A Constituição Federal de 1988 surge após um período de ditadura militar em que as ideias de liberdade e igualdade eram fortemente relacionadas à estruturação de uma democracia; partia-se da vontade da população brasileira para se estruturar uma sociedade em que imperasse a

\footnotetext{
${ }^{24}$ MARITAIN, Jacques. O homem e o estado. Tradutor Alceu Amoroso Lima. 2. ed. Rio de Janeiro: Livraria Agir, 1956. p. 147.

${ }^{25}$ MARTÍNEZ, Alejandro Rosillo. Praxis de liberación y derechos humanos: uma introducción al pensamiento de Ignacio Ellacuría. San Luis Potosí, México: Universidade Autónoma de San Luis Potosí, 2008. p. 100 -107.

${ }^{26}$ MARITAIN, Jacques. O homem e o estado. Tradutor Alceu Amoroso Lima. 2. ed. Rio de Janeiro: Livraria Agir, 1956. p. 161.
} 
igualdade entre as pessoas, que todos tivessem o direito ao voto e mantivessem sua dignidade imaculada.

A Constituição representa os anseios da Assembleia Constituinte, legítima representante do povo para estruturar uma norma que garanta a democracia no Brasil. Embora no decorrer dos últimos anos tenham se denunciado inúmeros casos de corrupção no poder público e de afronta aos direitos fundamentais, nada obsta que a Constituição Federal garanta a democracia. Entretanto, para essa democracia valer, é necessário que seja plena e eficaz, que proporcione o respeito às liberdades da população.

Tanto me leva a afirmar que se, de uma parte, a Constituição não realiza por si só ou pela sua só existência um governo democrático, de outra, ela não pode ser considerada a "culpada", nem sequer a "responsável única" pelo mau governo, pelo governo antidemocrático, pela atuação desastrosa e desastrada do mau governante. Constituição não ensina a governar, apenas assegura os princípios e preceitos que se põem para a realização possível do bom e democrático governo. ${ }^{27}$

É possível ainda afirmar que a democracia garante a realização dos valores supracitados de liberdade, igualdade e dignidade, que compõem as pilastras fundamentais para a manutenção da busca pela efetividade dos direitos fundamentais. Torna o conceito de Estado de Direito mais amplo, de modo que na concepção apresentada de democracia, evidenciase uma superação do liberalismo, que passou para um Estado Social de Direito e chegou hoje no que se denominou Estado Democrático de Direito. 28

Esta concepção de Estado Democrático de Direito não resume simplesmente a ideia de Estado de Direito com Estado Democrático. É um termo novo e inclui em seu conceito a superação do status quo. Nossa Constituição, ao preceituar que o Brasil se compreende em Estado Democrático de Direito está afirmando que há a necessidade constante de evoluir

\footnotetext{
${ }^{27}$ GRAU, Eros Roberto; FIOCCA, Demian (org.). Debate sobre a constituição de 1988. São Paulo: Paz e Terra, 2001. p. 9.

${ }^{28}$ SILVA, José Afonso. Curso de direito constitucional positivo. 32. ed. rev. atual. até a Emenda Constitucional n. 57, de 18 jan. 2008. São Paulo: Malheiros, 2009. p. 112.
} 
para a realização plena de princípios como a liberdade, igualdade e dignidade humana. ${ }^{29}$

\begin{abstract}
A democracia não pode ficar sujeita a um “adestramento universal” na busca da Idade de Ouro, onde "para haver comida é preciso aceitar a pax oferecida pelo conquistador".[...]

Desde que se pense a democracia como sentido de um vir-a-ser, a ruptura com o tempo instituído antepõe-se como limite possibilitador. ${ }^{30}$
\end{abstract}

Para a construção de uma sociedade mais digna e igualitária, como foi o desejo do constituinte, necessário é o processo legal, ou melhor, o devido processo legal, garantindo ao cidadão a proteção a vida, liberdade, propriedade, igualdade e segurança. Percebe-se que o limite para o Estado Democrático é o Estado de Direito.

Entretanto, o Estado Democrático de Direito representa o Estado Constitucional, aquele em que maior atenção é dada a necessidade de ver efetivos os direitos fundamentais, estejam estes direitos inclusos no âmbito dos direitos individuais, mas principalmente aqueles que se encontram estabelecidos como direitos sociais. ${ }^{31}$ Quase como uma necessária igualdade geométrica, ${ }^{32} \mathrm{em}$ que a parte e o todo compõem estrutura necessária para a manutenção da própria sociedade, ou seja, o individual e o social comportam ambos o interesse mútuo, que no caso em debate, trata-se de ver efetivos direitos ditos fundamentais, direitos humanos estruturados em linhas constitucionais.

Falar de democracia imputa ao pesquisador tratar de temas singulares e atinentes ao tema. Por exemplo, ao iniciar os debates deste traba-

\footnotetext{
${ }^{29}$ Idem. p. 119.

${ }^{30}$ STRECK, Lenio Luiz; MORAIS, José Luis Bolzan. Ciência política e teoria do estado. 7. ed.. Porto Alegre: Livraria do Advogado, 2012. p. 123-124.

${ }^{31}$ NERY JÚNIOR, Nelson; NERY,Rosa Maria de Andrade. Constituição federal comentada e legislação constitucional. 3. ed. São Paulo: Ed. Revista dos Tribunais, 2012. p. 177 -178 .

${ }^{32}$ ARITÓTELES. Ética à Nicômaco. Tradutor Torrieri Guimarães. 6. ed. Martin Claret: São Paulo, 2013. p. 100.
} 
lho imputou-se necessário o debate sobre a formação do Estado Democrático de Direito e das formas de manter efetivos os ditames constitucionais acerca dos direitos fundamentais.

Entretanto, para que tais direitos sejam garantidos e efetivados, devem os representantes do povo manterem-se na qualidade de detentores do poder para a construção de um país equânime para todos e não simplesmente preocuparem-se com a própria manutenção no poder. Tais indícios, constantemente revelados pela mídia, demonstram uma maior preocupação dos legisladores em agradar o eleitorado e não levar a debate o mérito de diversos problemas. Inúmeros são os casos relatados pelos meios de comunicação e averiguados pelo Ministério Público, OAB, Procuradorias e demais instituições acerca de corrupção e improbidade de agentes e servidores públicos.

São os membros dos Legislativo e Executivo, nas mais diversas unidades da federação, os detentores do poder - detentores legítimos desde que respeitado um devido processo eleitoral - que poderiam controlar a sistemática legal presente no país para ver efetivados os direitos fundamentais, com preocupação quanto à gestão dos bens e patrimônios públicos em prol da coletividade, mas que preocupam-se em "[...] ter o poder pelo poder [...]". 33

Parece que a democracia disciplinada na Constituição Federal indica a busca por uma sociedade em que prevaleça a igualdade de todos os cidadãos, que todos tenham uma vida digna. Nesse contexto, pode-se pensar na democracia como um princípio que permite a compreensão de quão importante é a manutenção do Estado Democrático de Direito e de superação das desigualdades. Ressalta-se a importância da dinamicidade da realidade histórica em que se encontra o ser humano, para a necessária demonstração de superação de paradigmas que inflam os descontentamentos dos cidadãos brasileiros para a busca e concretização de um país mais próximo dos ideais e objetivos inscritos na Constituição Federal, que se mantêm firmes, mesmo após tantas e tantas emendas constitucionais.

Aqui não se faz crítica ao processo de criação, apreciação e promulgação de emendas constitucionais, ainda mais ao considerar o Brasil um país jovem em termos de criação e sustentação de uma Constituição democrática - apenas cerca de 25 anos. A crítica existe no sentido de dina-

\footnotetext{
${ }^{33}$ MARTINS, Ives Granda da Silva. O estado do futuro. p. 13 - 28. In MARTINS, Ives Granda da Silva (Coord.). O estado do futuro. São Paulo: Pioneira: Associação Internacional de Direito e Economia, 1998. p. 18.
} 
mizar os debates, ainda que singularmente, ao que tange a quantidade desenfreada de emendas constitucionais que são apresentadas no Congresso Nacional sem levar em consideração a Constituição Federal como um todo, comprometendo a própria sistemática legal do país, que deve ter a Constituição como norte e as leis infraconstitucionais regulando as situações humanas cotidianas dos cidadãos no país.

\section{CONCLUSÃO}

Do exposto acima, é possível concluir que ao longo dos anos o estudo sobre o que se denomina democracia tomou formas e conceitos diversos, para atender às necessidades daqueles que buscavam sua melhor aplicação ou compreensão.

Não é de se estranhar que grandes juristas importaram-se com a temática, de modo que Hans Kelsen, Hermann Heller e Carl Schmitt buscaram incluir no conceito de democracia suas próprias ideias de como se estruturava o Direito, a sociedade e a Constituição.

Foram apresentados conceitos importantes nos estudos sobre o Liberalismo, o Socialismo, as formas de governo e as formas de Estado, que direcionaram o trabalho no sentido de demonstrar a necessária manutenção de um Estado preocupado em garantir alguns princípios importantes para a manutenção da vida digna em sociedade, como por exemplo, a igualdade, a liberdade e a dignidade humana.

Durante um mesmo momento histórico os juristas analisados incluíram em seus estudos a análise do que seria o melhor conceito para a democracia. Deveria ser a democracia instituída pela norma, mais especificamente uma norma constitucional superior; a sociedade, como conjunto de seres humanos, poderia instituir as garantias básicas que se somam a democracia na defesa dos direitos fundamentais do homem; um poder uno deve ser a fonte das determinações necessárias à democracia, tendo este poder por vezes se originado de um soberano e outras da própria pluralidade de indivíduos unidos socialmente.

O Brasil é um país que possui inúmeros problemas sociais, que influem diretamente nas condições econômicas e culturais da população brasileira. Entretanto, compreender que Estado Democrático de Direito não é expressão vaga incluída pelo constituinte ainda no primeiro artigo da 
Constituição Federal, implica na compreensão da necessidade de estruturação de um país garantidor de direitos fundamentais, da vida digna de seus cidadãos.

Estruturar um país democrático importa necessariamente em fazer valer a democracia em diversos aspectos. Quando a população se organiza e vai às ruas manifestar-se contra o aumento de tarifas do transporte público, contra os gastos exorbitantes em obras para eventos esportivos, enquanto hospitais públicos e o sistema educacional público do país estão sucateados, vislumbra-se uma movimentação popular democrática legítima. No mesmo sentido, é legitimamente democrática a organização dos cidadãos para criar mecanismos de controle da efetividade de políticas públicas no país, dos trabalhos realizados pelos deputados e demais membros do Legislativo, bem como dos membros do Executivo e do Judiciário. O ápice democrático ocorre quando a população compreende a real necessidade e importância do sufrágio, do poder de escolha de seus representantes no Poderes Legislativo e Executivo.

Após as manifestações de meados de 2013 até hoje, bem como de outras que poderão ocorrer logo mais, observa-se que a sociedade brasileira começou um processo de cognição para gerir mais eficientemente a própria máquina estatal, de modo que o Estado seja efetivamente Democrático de Direito. Para que os direitos fundamentais inscritos na Constituição Federal sejam resguardados e efetivados para a alteração da realidade histórica em que se encontra o país, deve haver integração das vontades públicas e privadas, harmonia entre os anseios de progresso econômico, desenvolvimento nacional e combate à desigualdade social, fome e miséria, promovendo um país mais igualitário e democrático para as gerações vindouras.

\section{REFERÊNCIAS BIBLIOGRÁFICAS}

ARITÓTELES. Ética à Nicômaco. Tradutor Torrieri Guimarães. 6. ed. Martin Claret: São Paulo, 2013.

AZAMBUJA, Darcy. Teoria geral do estado. 4. ed. Rio Grande do Sul: Editora Globo, 1966.

BERCOVICI, Gilberto. Soberania e constituição: para uma crítica do constitucionalismo. São Paulo: Quartier Latin, 2008. 
. Democracia, inclusão social e igualdade. Conselho Nacional de Pesquisa e Pós-graduação em Direito - CONPEDI. Anais do XIV Congresso Nacional do CONPEDI. Anais dos eventos. On-line. $2005 . \quad$ Disponível

em $<$ http://www.conpedi.org.br/manaus/arquivos/anais/XIVCongresso /043.pdf >. Acesso em 24 set. 2012.

BONAVIDES, Paulo. Do estado liberal ao estado social. 9. ed. São Paulo: Malheiros, 2009.

DALLARI, Dalmo de Abreu. Elementos de teoria geral do Estado. 30. ed. São Paulo: Saraiva, 2011.

FERREIRA FILHO, Manuel Gonçalves. Estado de direito e constituição. 2. ed. rev. e ampl. São Paulo: Saraiva, 1999.

GRAU, Eros Roberto; FIOCCA, Demian (org.). Debate sobre a constituição de 1988. São Paulo: Paz e Terra, 2001.

HELLER, Hermann. Teoria del Estado. México: Fondo de Cultura Economica, 1942. Manuales introdutórios, v. II.

KELSEN, Hans. A democracia. 2. ed. São Paulo: Martins Fontes, 2000.

KELSEN, Hans. Quem deve ser o defensor da constituição?. 2. ed. (Reimpressão). Coleção Clássicos do Pensamento. Madri: Technos, 2002.

Teoria geral do Estado e do Direito.Tradutor Luiz Carlos Borges. 2. ed. São Paulo: Martins Fontes, 1992.

MARITAIN, Jacques. O homem e o estado. Tradutor Alceu Amoroso Lima. 2. ed. Rio de Janeiro: Livraria Agir, 1956.

MARTINS, Ives Granda da Silva. O estado do futuro. p. 13 - 28. In MARTINS, Ives Granda da Silva (Coord.). O estado do futuro. São Paulo: Pioneira: Associação Internacional de Direito e Economia, 1998.

MARTÍNEZ, Alejandro Rosillo. Praxis de liberación y derechos humanos: uma introducción al pensamiento de Ignacio Ellacuría. San Luis Potosí, México: Universidade Autónoma de San Luis Potosí, 2008.

MATOS, Andityas Soares de Moura Castro. Filosofia do direito e justiça na obra de Hans Kelsen. 2. ed. Belo Horizonte: DelRey, 2006.

NERY JÚNIOR, Nelson; NERY,Rosa Maria de Andrade. Constituição federal comentada e legislação constitucional. 3. ed. São Paulo: Ed. Revista dos Tribunais, 2012.

REALE, Miguel. O estado democrático de direito e o conflito de ideologias. 2. ed. São Paulo: Saraiva, 1999. 
SCHMITT, Carl. La defensa de la constitución: Estudios acerca de las diversas especies y posibilidades de salvaguardia de la Constitución. Madri: Technos, 1983.

SILVA, José Afonso. Curso de direito constitucional positivo. 32. ed. rev. atual. até a Emenda Constitucional n. 57, de 18 jan. 2008. São Paulo: Malheiros, 2009.

STRECK, Lenio Luiz; MORAIS, José Luis Bolzan. Ciência política e teoria do estado. 7. ed.. Porto Alegre: Livraria do Advogado, 2012. 
